\section{Survival in Young Patients With Noncompaction May Not Only Depend on Cardiac But Also on Neuromuscular Comorbidity}

\section{To the Editor:}

With interest we read the article by Wang et al ${ }^{1}$ about the long-term prognosis of patients with left ventricular hypertrabeculation/noncompaction. They compared baselines findings and outcome events of 108 LVHT patients with the infantile type who presented at age $<1$ year with 97 cases of juvenile-type LVHT, in which the patients presented at age $1-15$ years. They found that LVHT of both types showed a poor long-term prognosis and recommended follow-up of these patients into adulthood.

We have the some questions and concerns.

It remains unclear according to which rationale the distinction between "infantile" and "juvenile" type was set at age 1 year. Furthermore, the time span for the "juvenile" type covers a long period, from 1 to 15 years, including the time of puberty.

It is reported that 42 patients presented in the neonatal and 10 in the fetal period. In how many of the neonatal cases was fetal echocardiography carried out and how many of them developed LVHT only after birth? ${ }^{2}$

It is indicated in the Methods that none of the patients had neuromuscular disorders (NMDs) or other systemic syndromes. This is very unusual, given the high rate of different neuromuscular and chromosomal abnormalities so far reported to be associated with LVHT. ${ }^{3}$ Thus, it would be interesting to know which tests were carried out in the included patients to substantiate the statement. What were the creatine kinase values in the included patients? How many of the included patients were seen by a neurologist? In how many of the included patients was the family history positive for muscle disease?

The questionnaire included questions for facial dysmorphism. However, neither in the Results nor in the Discussion were any data presented or discussed about dysmorphism, If it was not found in any of the 205 patients this would be very unusual. Facial dysmorphism is often an indicator of a genetic defect.

LVHT can affect not only a single family member but several of them. ${ }^{4}$ In how many of the included patients was the family history positive for LVHT? In how many of the cases were family members systematically investigated for LVHT? What is meant by family history in Table 1 ?

We are confused regarding the symptoms at diagnosis as listed in Table 1. In the infantile group, we miss information for almost 5\% and in the juvenile group we miss information for nearly $15 \%$ of the patients. How many of the patients, initially asymptomatic, developed cardiac symptoms during follow-up? In the infantile group, the rate of systolic dysfunction at baseline was higher than in the juvenile type. How many of the patients developed deterioration or improvement of systolic function during follow-up? How do the authors explain that $60 \%$ of the infantile cases had symptoms and signs of heart failure whereas the majority of the juvenile cases was asymptomatic? This is particularly curious as survival rates were similar in both groups. Did all those with heart failure die early?

It is reported that an echocardiographic "noncompaction score" was developed to estimate the severity of LVHT. However, in Table 2, the noncompaction score is only reported for 89 patients. What were the echocardiographic findings in the remaining 116 patients?

It remains unclear why implantation of a cardioverter/ defibrillator (ICD) was counted as an endpoint, and implantation of a pacemaker, on the contrary, not. Furthermore, it would be of interest to know if there were any discharges of the ICDs and if the patients who died from arrhythmia had ICDs or not. It would be interesting to know if the patients who died from arrhythmia had a normal or decreased left ventricular function. It is also of interest how many of those who reached an endpoint suffered from a NMD.

Seven of the patients showed left bundle branch block (LBBB). Was institution of cardiac resynchronization therapy (CRT) considered in these patients? In adult LVHT patients with a LBBB, CRT has been shown to be a beneficial intervention. ${ }^{5-7}$

In conclusion, we think that more information about this interesting and large cohort with LVHT might increase our knowledge about the natural history of VHT in children.

\section{Grants / Funding / Conflict of Interest}

None.

\section{References}

1. Wang C, Takasaki A, Watanabe Ozawa S, Nakaoka H, Okabe $\mathrm{M}$, Miyao N, et al. Long-term prognosis of patients with left ventricular noncompaction: Comparison between infantile and juvenile types. Circ J 2017; 81: 694-700.

2. Stöllberger C, Wegner C, Finsterer J. Fetal ventricular hypertrabeculation/noncompaction: Clinical presentation, genetics, associated cardiac and extracardiac abnormalities and outcome. Pediatr Cardiol 2015; 36: 1319-1326.

3. Finsterer J, Stöllberger C, Towbin JA. Left ventricular noncompaction cardiomyopathy: Cardiac, neuromuscular, and genetic factors. Nat Rev Cardiol 2017; 14: 224-237.

4. Finsterer J, Stöllberger C, Blazek G, Sehnal E. Familial left ventricular hypertrabeculation (noncompaction) is myopathic. Int J Cardiol 2013; 164: 312-317.

5. Stöllberger C, Blazek G, Bucher E, Finsterer J. Cardiac resynchronization therapy in left ventricular hypertrabeculation/noncompaction and myopathy. Europace 2008; 10: 59-62.

6. Qiu Q, Chen YX, Mai JT, Yuan WL, Wei YL, Liu YM, et al. Effects of cardiac resynchronization therapy on left ventricular remodeling and dyssynchrony in patients with left ventricular noncompaction and heart failure. Int J Cardiovasc Imaging 2015; 31: 329-337.

7. Penela D, Bijnens B, Doltra A, Silva E, Castel MA, Berruezo A, et al. Noncompaction cardiomyopathy is associated with mechanical dyssynchrony: A potential underlying mechanism for favorable response to cardiac resynchronization therapy. $J$ Card Fail 2013; 19: 80-86.

Claudia Stöllberger, MD

Josef Finsterer, MD, PhD

Rudolf's Foundation, Wien, Austria

Received February 17, 2017; accepted May 8, 2017; released online July 8, 2017

Mailing address: Claudia Stöllberger, MD, Krankenanstalt Rudolfstiftung, Juchgasse 25, A-1030 Wien, Austria. E-mail: claudia. stoellberger@chello.at

ISSN-1346-9843 All rights are reserved to the Japanese Circulation Society. For permissions, please e-mail: cj@j-circ.or.jp 